\title{
Race, space and place in suburban Durban: an ethnographic assessment of gated community environments and residents
}

\author{
Matthew Durington
}

\begin{abstract}
This paper explores gated community culture and development in the suburbs of North Durban in the KwaZulu-Natal province of South Africa. Using perspectives from the anthropology of space and place as a theoretical and methodological framework, ethnographic fieldwork in one community in this area explores the cultural reasoning behind the movement to a fortified suburban enclave in South Africa by problematizing why, in a newly democratic society based on an ethos of desegregation, do individuals feel the need to segregate themselves along class and racial lines in fortified developments in a fashion reminiscent of homeland demarcation during apartheid? And, is the movement to gated communities within post-apartheid South Africa solely a white cultural and class phenomenon? While these questions are necessary, and perhaps commonsensical in terms of the unique social history of South Africa, research also attempts to complicate these lines of inquiry to apprehend the cultural reasoning and lifestyles of gated community residents to move past racial and class stereotypes and delve into the complex culture of these environments and the different rationalizations that individuals work with to justify their surroundings.
\end{abstract}

Keywords Ethnography - Gated communities · Race $\cdot$ South Africa

\section{Introduction}

On April 27, 2004 President Thabo Mbeki was sworn in for his second term as president of the Republic of South Africa symbolically marking the 10-year anniversary of the new democracy and the demise of the former apartheid system. In the months leading up to this symbolic marker of progress in the "New" South Africa the 10-year democracy marker dominated the country in terms of press and media. There were multiple statements of national unity and pride in the accomplishments made by the government and its citizens during the previous decade. Every social phenomenon or event in South Africa, positive or negative, was couched in the notion of where it stood in relation to 10 years of democracy. Anecdotally, according to various media advertisements, "South Africa is alive with possibility," "There is more holding us together than keeping us apart," and consumers within the burgeoning democracy could also participate in "10 years of MTN cellular freedom" whilst revering the new status of the country and purchasing a series of 10 commemorative Coca-Cola cans emblazoned with the 10 greatest moments of democracy in recent South African history. Despite progress on many fronts, the cultural and institutional memory of apartheid remains a symbolic and material obstacle in terms of socioeconomic development. During the previous decade years South Africa has undergone rapid social change that has caused a number of transformations for racial groups previously dispossessed of land and subjugated under apartheid (Daniel, Habib, \& 
Southall, 2003). Yet, notwithstanding current aspirations by the burgeoning South African government to create an equitable and non-racial society and the utopian marketing strategies of many corporations, a separation along class and racial lines has intensified (Nattrass, 2003).

Despite the emergence of a small black middle class, the gap between rich and poor predominantly follows racial divisions with a white minority possessing economic dominance while a mostly rural, black majority overwhelmingly rep- resents the country's poor (Desai, 2000). This economic and racial split has become apparent in land reform (Aliber \& Mokoena, 2003) and housing development as home shortages in black communities (Hindson \& McCarthy, 1994) parallel rapid home development in affluent suburban environments. The movement of large numbers of the rural black population into urban areas has paralleled the movement of capital out of central business districts in South Africa's major cities resulting in what could be deemed white flight to outlying suburban communities both in terms of residents and businesses. There are several factors that contribute to the process of white flight including commercial relocation, real estate development and perceptions of different social trends. ${ }^{1}$ Similar to trends in other major global cities, this movement to suburbs in South Africa has been bolstered by a perception of increasing crime that has rationalized the development of gated communities by property developers and justified the move to fortified suburban enclaves for new suburban residents. It could be said that crime and the avoidance of its consequences is one of the most important issues of concern among residents of gated communities, if not all residents in South Africa. Thus, the goal of this paper is to attempt to understand these particular concerns and other rationalizations for inhabitants of gated community environments in South Africa through examples drawn from ethnographic research conducted in one community in the northern suburbs of Durban.

1 According to Brodkin (1998) the notion of 'white flight' refers to a process whereby newly defined 'whites' and capital moved from urban centres to suburban environments in the United States following World War II. In reference to Durban, Freund and Padayachee (2002) have described the period in the 1980s in Durban when the informal economy was recognized signifying a historic major reversal in economic strategy. I believe this factor in addition to the impending demise of apartheid and shifts in capital signalled white flight in Durban specifically. This contemporary movement in Durban is not solely bounded by conceptions of race but can be seen as a general class movement toward a new capital centre surrounded by newly located businesses, retail and other lifestyle amenities. The spatial parameters of Durban also account for the direction of this flight north of the city as the south coast was already developed and traditional lands or previous suburbs such as Westville and Pinetown accounted for most of the land west of the city. Thus, the land north of the Umgeni River in Durban, essentially a blank slate of sugar cane fields owned by Tongaat-Hulett and developed by their property division Moreland started to be transformed into home developments alongside Umhlanga and other towns. The area north of Durban became the major destination of would be suburban residents at this time. As of 2004, it is widely speculated that the future of the Durban metropolis lies to its north with a new casino and airport being developed alongside new residential developments as the city continues to sprawl.

\section{Race, space and place}

Throughout the unique social history of South Africa the country has been governed by ideas and control of space, both in terms of its symbolic power and its geographical realities. What is made clear by exploring this history is the way in which space has been imbued with meaning conveying either subjugation or freedom depending upon the particular historical conditions. 
The original aspiration of colonial powers was to carve a space for cultural purposes, commercial enterprises and expansion of empire, to imagine communities in a new space separate from the metropole (Anderson, 1983). Through various forms of legislation highlighted by the Group Areas Act, the previous apartheid government of South Africa sought to exercise a system of social control and discrimination of racial groups based on the geographical separation of social spaces. Essentially, South African apartheid was a geographical process. As geographer Glen Elder has aptly stated, "For many South Africans who lived under the weight of apartheid, geography translated into devastating effects. Forced removals, evictions from ancestral homes, and the active destruction and re-invention of neighbourhoods and communities are just some ways that geographical processes were experienced by South Africans living under apartheid" (Elder, 1997, p. 1).

Contemporary post-apartheid legislation and socioeconomic developments in the " New" South Africa rely upon symbolic reinscriptions of geography and social space to assert a new democratic ethos for the country as previous home- lands have been renamed and landmarks associated with the subjugation of apartheid such as Robben Island are reimagined and redefined to symbolically stand for democratic change and a source for tourist income. In these myriad capacities, social and geographic space is conceptualized differently and imbued with the capacity of socially producing meaning and change (Soja, 1989). Yet, as Hook and Vrdoljak state, "The new racial politics of space are predicated not so much on categorical racial prohibitions as on highly individualized and specified rights of admission" (Hook \& Vrdoljak, 2001, p. 68). The contemporary gated community development in South Africa embodies this new racial politics of space. Yet, it is also a space imbued with meaning in a number of different ways by residents of these developments; it also demands a more complex level of understanding offered by ethnographic investigation.

A body of work has emerged in recent years on various topics in anthropology that theorize or focus on notions of space and place and the means by which the field can contribute to an interdisciplinary dialogue that includes urban planners, geographers and architects. The theoretical direction of an anthropology of space and place argues that the social spaces individuals inhabit, traverse and create on a daily basis come with a concomitant set of behavioural expectations, social roles and ideologies. Increasingly, "[...] anthropologists have begun to shift their perspective to foregrounding spatial dimensions of culture rather than treating them as background, so that the notion that all behavior is located in and constructed of space has taken on new meaning" (Low \& Zuniga, 2003, p. 1). Essentially, spaces are conceptualized as embodied, gendered , in- scribed, contested, transnational and controlled through various tactics and are deemed suitable for exploration by anthropologists seeking to investigate the relationship of social space to various cultural processes (Low \& Zuniga, 2003). Of interest to this particular study are two trajectories identified by Low and Zuniga that are concerned with how spaces are inscribed with meaning and contested.

The control of space is an inherently political process with the capacity to confirm identity and convey ideology. Spaces become inscribed with meaning. "Inscribed spaces implies that humans 'write' in an enduring way their presence on their surrounding [...] how people form meaningful relationships with the locales they occupy, how they attach meaning to space" (Low \& Zuniga, 2003, p. 13). This perspective is informed by a number of theorists historically. Foucault has demonstrated how the built environment is symbolically instilled with the capacity to produce and exercise power in the form of regulatory mechanisms such as the panoptican prison model (Foucault, 1979). The movement of individuals around geographic spaces also endows them with cultural meaning, essentially imbuing space as place, as Munn has demonstrated through the means by which Australian Aborigines will create "negative space" by avoiding certain locales (Munn, 1996). In a similar sense, Soja discusses the social production of space offering the operational term "spatiality" as a mechanism to de- scribe how spaces are 
inscribed with power and meaning (Soja, 1989). Social spaces are also con- tested. As Low and Zuniga continue, "We define 'contested spaces' as geographic locations where conflicts in the form of opposition, confrontation, subversion, and/or resistance engage actors whose social positions are defined by differential control of resources and access to power" (2003, p. 18). This definition allows for the reality that certain spaces not only have different meanings, but also reflect competing realities for individuals and the varied perceptions of these spaces both in terms of symbolic value and practice. While one space may imbue pride for one individual, it may stand as a symbolic cultural marker of exploitation for someone else, especially when considering the social history of South Africa. These differences may focus merely on the meaning attributed to a space, but can also stand for larger social disparities in terms of political, class, race and gender equality.

In keeping with anthropological approaches to space and place, it is implied that sites like gated communities are endowed with meaning only when local inhabitants invoke their understanding of them in practice, practice being the combination of meaning and action as expressed by Bourdieu (1990). In other words, local meaning is generated by gated community inhabitants when rationalizations for living in these environments are asserted by individuals in their daily practices and conversations. It is asserted that the cultural memory of apartheid and the institutional policy of demarcating space and establishing boundaries by race that occurred in the past influences conceptions of space and place in contemporary South Africa. Is the habitus of gated community inhabitants invariably linked to this history? How is cultural capital acquired and brokered within these spaces? Just as fear of crime compounded by racial and class ideology has rationalized the construction of gated communities in the United States and elsewhere, it is postulated that the social history of South Africa, coupled with contemporary perceptions of race, class and crime, creates similar rationalizations for inhabitants of these spaces and in turn supports gated community development. Thus, the remainder of this paper provides an anthropological analysis of suburban identity within gated communities and the institutional mechanisms that support their creation in the context of post-apartheid South Africa.

With these notions in mind, how does the inscription and contestation of social space translate into gated community development and residence within South Africa? Gated communities are markers of social progress and affluence for individuals that can afford to live within them. They are perceived to be symbolic cultural bastions and safe havens from crime and other social ills affecting social spaces outside of their confines. In turn, their construction also supports the growth of a fear industry made up of armed security companies and others that create and maintain security apparatuses supporting a general "culture of fear" (Glassman, 1999). For those that live outside of gated communities these spaces can serve as markers of segregation and continued class exploitation, or a hard barrier between the haves and have-nots within a society. They become places that solidify all that is perceived to be wrong within a particular society in terms of racial and class disparity. While all of these perspectives have merit, it is the task of an anthropological examination to attempt to understand the local meanings created within these spaces while contextualizing existing perspectives. A number of questions arise: what are the perceptions of gated community inhabitants? Why do people choose to live in gated communities and what are the concerns and life ambitions of residents? Are they safer environments? What is the racial makeup of these developments? Are these white cultural bastions that are merely a reinscription of apartheid and the Group Areas Act? ${ }^{2}$ Or, is it about class as opposed to race? What are the social tensions that exist within gated communities and is it really "just about the golf?"

2 Hook and Vrdoljak (2001) question this in their analysis of gated communities in and around Johannesburg. Their article is not ethnographic in intent, but provides a framework for considering issues of 'spatiality' and gated communities in South Africa. 


\section{Gated communities in South Africa}

The increasing trend in gated community development in South Africa reflects the growing development of these social spaces throughout the world as fortified suburban enclaves are inhabited predominantly by the upper class and surrounded by a number of security apparatuses including high walls, boom gates, razor wire, electric fences, 24-h guards and armed response security companies (Blakely \& Snyder, 1997; Caldeira, 1996; Low 1997, 2003a, 2003b). While many of these security devices exist around homes throughout the city and suburbs, especially in South Africa, it is important to make a distinction between the fortified home as opposed to the fortified community. Whereas almost every home in and around Durban is fortified, or in South Africa for that matter, gated communities consist of homes that were built as part of a planned fortified development where security apparatuses may exist in the home but the main source of security comes from an enclosed wall and/or fence, usually masked or out of sight, with limited points of controlled access entry. It is also important to distinguish the gated community consisting of residential dwellings from the fortified business park or apartment complex (Landman, 2000a, 2000b) (Fig. 1).

There is also a difference between enclosed neighbourhoods and security villages. Security villages refer to private developments usually centred on a business while enclosed

Fig 1 A gated community barrier surrounding Springfield Hills

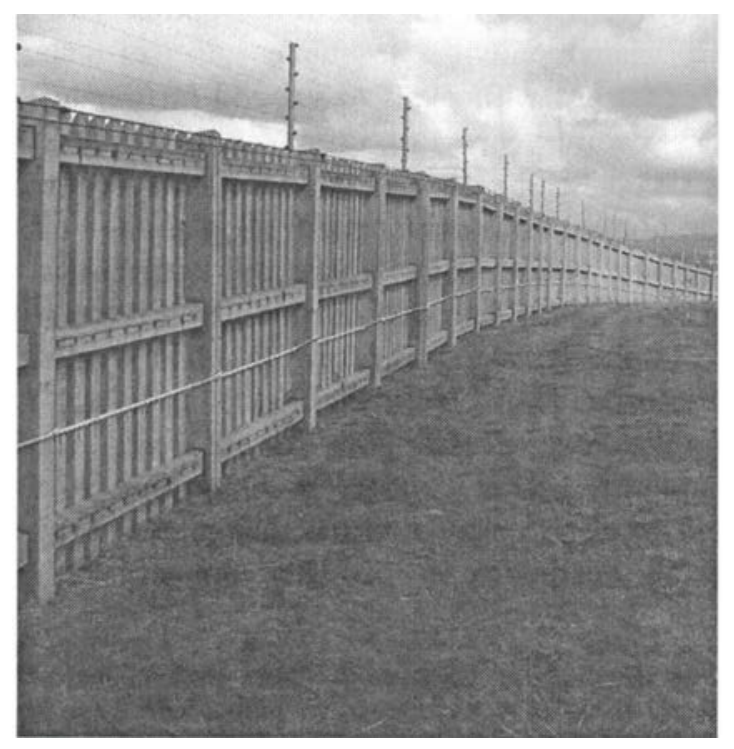

neighbourhoods refer to residential environments (Landman, 2000a). Of the latter type of residential gated communities there are four that re- search has identified within Durban:

(1) the typical fortified apartment block within or immediately adjacent to the city centre,

(2) neighbourhoods aspiring to become gated com- munities by soliciting the city of

Durban for per- mission to erect boom gates and other security measures on public streets,

(3) golf estates found in the suburbs and made up of a number of homes built around a golf course with a unified theme in construction and appearance and (4) the eco-estate which 
usually has the same lifestyle amenities as the golf estate, but has a branding and marketing strategy emphasizing the environment as opposed to security measures as its principal selling point. The eco-estate is part of a larger trend in tourism and other industries that seeks to highlight environmental awareness and/or practices that work in unison with the environment with the goal of limiting harm to nature. ${ }^{3}$ For eco- estate developers and residents, normal conceptions and descriptions of gated communities are substituted by displacing notions of security and separateness that might be seen as divisive into unifying and safe concepts wrapped around notions of ecology and the environment which are seen as safer issues to deal with rather than aspects of crime, fear or racial exclusion. This thinking allows the eco-estate resident to state who she/he is, "working as one with the environment" or "cohabitating with nature through their residence." Or, as another resident of a gated eco-estate stated,"/ don't have to think about security anymore. The reason I live here is because I don't have to see it but I also live here because I love the bush and I can be around nature all the time [...] that is the real reason. Plus, my husband loves the access to the golf course" (e.g., Informant 1, per- sonal communication).

3 For the tourism industry, the term 'eco' has become a substitute for 'culture' as tourists are offered experiences that supposedly delve deeper into the cultural experience of indigenous people that live within certain environments. While a portion of this ethnographic research has taken place in two eco-estates, the primary focus in this paper is on a gated community that is not marketed or designed in this fashion.

One must also recognize the particular conditions in which gated communities are created and exist in contemporary South Africa. These conditions are based upon geography, history, culture, national legislation and local governance. Each major city in South Africa has a particular geography that determines the type of gated community development that occurs. While Johannesburg is defined by gated community sprawl and grows closer to Tshwane (formerly Pretoria), an ocean and mountains bound Cape Town, and Durban expands north into redefined sugar fields. The history of each city is unique and determines what social and cultural spaces may become more contested as places are redefined. Culture is perhaps the most important consideration as the ethnic, traditional and linguistic differences between these cities are significant as well. Yet, while different in many regards, they are all encompassed by an attempt to nationally legislate gated community development in terms of social justice. In no other country in the world would road enclosures or gated community development be elevated to the possibility of a human rights violation. And, finally, the capacity of local governance rests on each of these conditions. The important question arises: are gated communities and private development welcomed or unwanted by local government councils?

The main focus of much of the work on gated communities in South Africa and elsewhere tends to focus on the institutional and structural development of these social spaces. That is, we can look from the outside in to these communities and investigate their creation as well as marketing and place among other structures within city environments. While this contextual research is absolutely necessary in order to situate trends and the history of gated communities, they tend to lack the perspective of the everyday life and rationalizations of gated community inhabitants, the unique perspective that comes from an anthropological focus on ethnographic qualitative research. ${ }^{4}$ Research concerned with these elements is meant to emphasize the voice of gated community residents and hence the control of perceptions of social space to inhabitants, a necessary step before critiques or other notions can be developed. As suggested by Rodman, anthropologists should "empower place by returning control over meanings of place to the rightful producers, and empower their own analysis of place by attending to the multiplicity of inhabit-ants' voices found in places about place" (Rodman cited in Low, 2003b, p. 390). 
4 There are a number of obstacles for research to be conducted in these environments, namely access and cap- ital. Gated communities are built to be impenetrable both in terms of crime and danger, but also in terms of investigation and exploration. One cannot simply walk into a gated community to look around or to initiate ethnographic research. For a good discussion of this issue see Low (2003a)

\section{Ethnographic trajectories in springfield hills ${ }^{5}$}

5 The name of the community where research was conducted as well as the names of individuals have been substituted with pseudonyms in accordance with confidentiality agreements and ethical concerns in ethnographic research.

Male Informant: "The most important issue in South Africa today is security. This entire community is based on the idea of security. If you don't have security you cannot survive here" (e.g., Informant 2, personal communication).

Springfield Hills is one of the most desired residential developments in metropolitan Durban. The development is divided into two estates with a typical 3-bedroom house selling for around 1.7 million rand (approx. \$242,000) in the fastest growing area of the Durban metropolis. The entire development is made up of about 1,300 homes with plans to expand further in the next several years. Properties within the two estates consist of existing freehold homes, sectional title homes, both existing and off plan, as well as freehold vacant land. There are restrictions in terms of home size and outside appearance with the homes having to conform to what is called a "Victorian Natal Veranda Style," although the modification of this plan by residents occurs frequently and is a source of contention as resi- dents seek to violate construction rules or limited design aesthetics in property appearance. As conveyed by one estate manager, a recent sale of vacant land plots started with prices at around 700,000 rand with most of these selling off within a 24-h period before the developer pulled about nine plots back and listed them again for about 1.4 million rand which sold just as rapidly providing further evidence of a strong desire to move to this community in suburban Durban (Fig. 2).

Fig 2 Gated community home types in Springfield Hills 


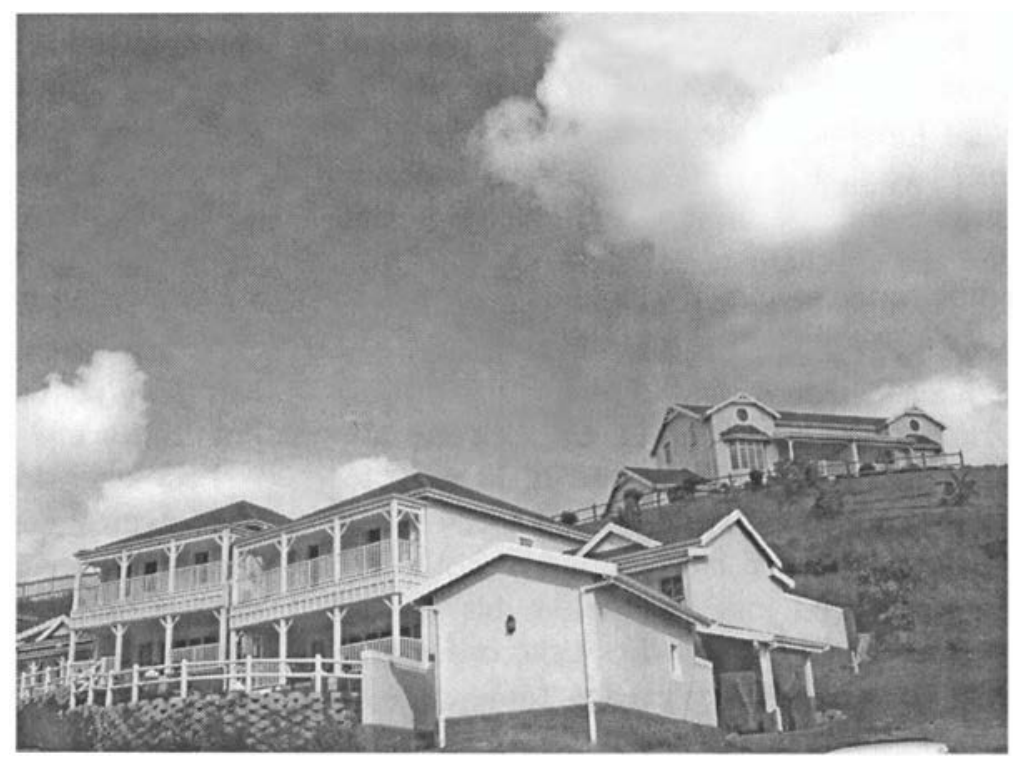

Ethnographic research has been conducted to apprehend the cultural reasoning and lifestyles of gated community residents to move past social stereotypes and delve into the cultures of these environments and the different rationalizations that individuals work with to justify their surroundings and how these relate to conceptualizations of gated community environments in South Africa. Some residents see the movement to gated communities as an investment opportu- nity with many residents living in one property but owning one or two more in the estate which are leased out to temporary residents or holiday makers. Others look at the gated community development as a retirement destination with lifestyle amenities such as golf and a sense of belonging that may not exist elsewhere. And, as articulated principally by gated community resi- dents in Springfield Hills, reasons for moving there are overwhelmingly justified through perceptions of crime and the need to escape other parts of the city that "have been overrun" or are no longer perceived to be safe even with multiple security measures in place. In this sense, there is a constant anxiety about the possibility of what could happen in the outside world now deterred by their new surroundings.

\section{Waiting?}

In the ethnography Waiting: The Whites of South Africa, the anthropologist Vincent Crapanzano uses the notion of "waiting" as a trope to discuss the political and racial dimensions of white culture in the waning years of apartheid to investigate "the effects of domination on every-day life-not the everyday life of people who suffer domination but of people who dominate" (Crapanzano, 1985, p. x). Although almost 20 years removed from Crapanzano's landmark ethnography, I question how have things changed? While the minority white population may not rule politically, do they still dominate socioeconomically? What are the levels of choice that exist for white South Africans as opposed to the so-called "Coloured" population or the dominant "African" population? Are whites in South Africa still waiting for something whether it is some form of resolution or impending problems? I also see similarities in the way whites are waiting as identified by Crapanzano. He described the circumstances under apartheid in the early 1980s, "Waiting is always waiting for something. It is an anticipation of something to come-something that is not on hand but will, perhaps, be on hand in the future. It is marked by contingency-the perhaps-and all the anxiety that comes with the experience of contingency" (Crapanzano, 1985, p. 45). What is it that gated community residents, the 
majority who are white, are waiting for 20 years later in post-apartheid South Africa?

It is a beautiful Wednesday afternoon much like the majority of afternoons in KwaZuluNatal and I am waiting on the tee box of the first hole at the Springfield Hills golf course with about twenty middle class white males. These men have an average age of about sixty and some refer to themselves as members of the "60 plus club" of Springfield Hills. They talk amongst one another in a fashion reminiscent of the gentility that surrounds posh places such as country clubs or executive business rooms that I have witnessed. The weekly golf tournament organized by one of my main informants is about to start as I am introduced to the crowd as an anthropologist from the U.S. "looking at how we live in golf estates." The jokes that are concomitant with the discourse and etiquette that sur- rounds a round of golf start instantly from across the crowd. "This is what we call in South Africa an informal settlement [...] just want to make sure you know that!" (e.g., Informant 3, personal communication), "Now, we aren't going to stop the round for you to dig for bones in the sand traps ok?" (e.g., Informant 4, personal communication). Humour elides social tension and becomes the mechanism for determining one's views and political leanings as well. As the round progresses over the next $5 \mathrm{~h}$ the political and ethnic jokes emerge and I play the sound ethnographer and take it all in. Ethnic jokes are incredible indicators of where one might stand in relation to a number of cultural and social views dependent on how one laughs politely, not at all or with gusto. The jokes heard on this day in Durban attempt to reassert the social order of a past time by symbolically placing those now in power in positions of ridicule.

As I look around throughout the day I view and experience several other markers of elite class status. The expansive homes that line the fairways possess top of the line outdoor grills and new Mercedes and BMW logos peek out from driveways. Surprisingly, I am told by some of the men that I am playing with that we are walking through a "ghetto" as they compare the new properties of this estate with the older estate that they live on within the same gated community development. Although the entire development shares the same exterior security walls, there are divisions within this perceived homogenous community. Tensions within communities speak to the cultural complexity of social environments. Through further interviews and participant observation, I ascertain how tensions over gardening or security access lead to discussions of race and the politics of the country. This leads to further conversations about the other differences between the old estate and the new estate; the difference be- tween controlled property specifications and the ability to follow and accept control in a planned community, the difference between the old money of the old South Africa and the new money of the "New" South Africa, the differences between different racial groups in the country, and the difference between quiet streets and ones that are "filled with all of those damn kids skateboarding everywhere and wreaking havoc" (e.g., Informant 2, personal communication). The markers of class status are also present in other conversations as one of my playing partners laments the fact that we had to wait so long to tee off because he was waiting for his wife to finish her morning round with the golf cart. My golf cart companion states, "You know I have been saying this to my wife for a few years but we really need to be a two-cart family" (e.g., Informant 4, personal communication).

Lest one think that these men are merely stereotypical self-involved upper class gate community inhabitants, the conversations turn to matters that they believe I might be interested in and hold political importance for them. Since I am a foreigner on the continent, a fact that has undoubtedly provided me with some level of access in Springfield Hills ${ }^{6}$

6 The question of access, again, is a major issue concerning research in gated communities and other environments. Another issue to be discussed in further work is how foreign status can provide access in locales other than one's own country and what this means for ethnographic research for someone attempting to do work in both one's home country and a foreign locale. 
I am told that I may not be aware of the 10-year cycle of postcolonial African countries. One of the foursome states, "It is a proven fact that once a country gains its independence that it usually goes all to hell in 10 years" (e.g., Informant 5, personal communication). I suppose that this may have been the other symbolic marker that some of South Africa's populous were anticipating in 2004 instead of peaceful elections. This sentiment also makes more sense out of the stories I have heard about the white population hoarding cash and stocking up on months of food and water prior to the 1994 elections 3 years after Mandela's release. Part of the mentality for those living in gated communities is informed by waiting for crime or waiting for the current government to collapse like others have throughout the continent (Fig. 3).

Fig 3 An entry gate at Springfield Hills

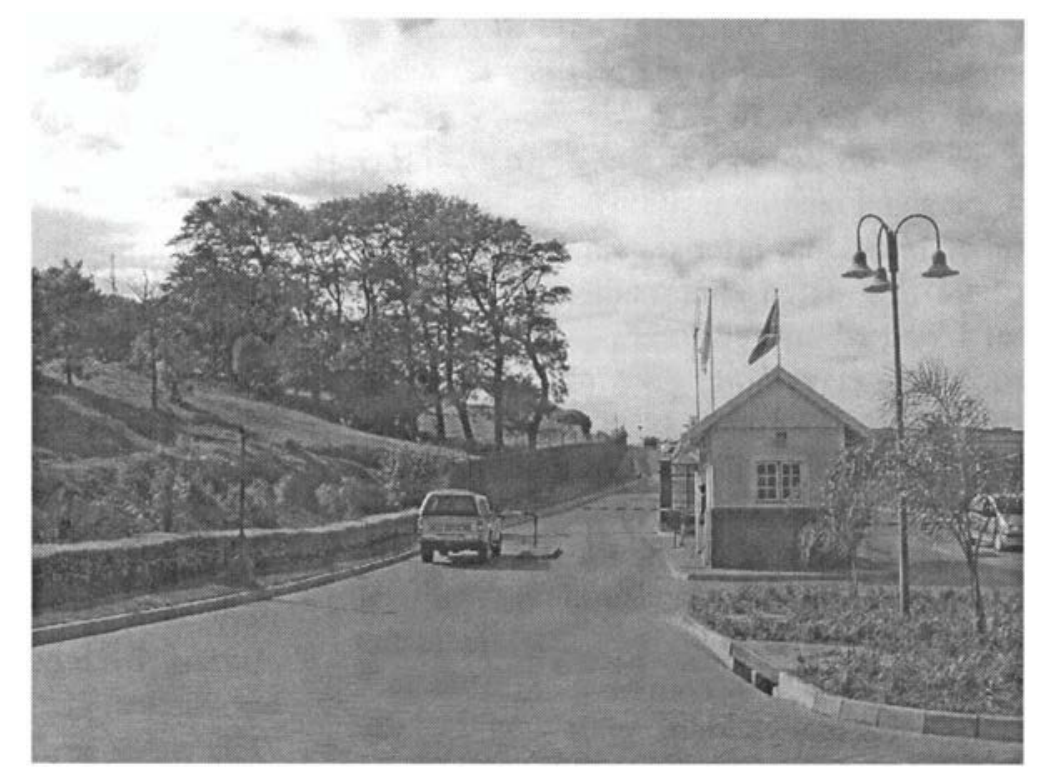

As I finish playing golf with these men reflecting on the fact that I never thought that golf would become a methodological tool in ethno- graphic research, I also see other people waiting, all black non-residents of the community, gardeners and domestic workers in long queues at a gate waiting to slide identity cards through a screening machine. It is an intense and well- honed process as vehicles wait outside of the gates to then take individuals to the main road for access to taxis and other forms of transportation. Someone sees me watching this process and tells me that it makes him uncomfortable as well. If individuals coming onto the estate in the morning do not slide their cards to check out by a certain time in the evening security is notified and "they have to be accounted for." I ask what that means and he tells me that security will move quickly to track them down because there could be theft or other crime occurring. Relating the events to his current hobby, he tells me how golf clubs have gone missing from bags after rounds and, inevitably, the Black caddies were blamed first al- though he never believed this accusation was directed toward them. He goes on to ponder, "Where would they hide the clubs while checking through the security gate? How could they steal the clubs, I mean, they would have to stick them in their uniforms and walk around like Frankenstein or something" (e.g., Informant 4, personal communication), as he demonstrates how this walk would be done. His display ceases and he reflects on the spectacle and states in a softer tone,"/ hate this [...] these people are in homes all day long and are not allowed to simply walk off the estate with dignity [...\} it reminds me of the days of the pass laws when everyone had to follow rules for when and where they could be [...] this should not be part of where this country is going" (e.g., 
Informant 4, personal communication).

Another individual later tells me at the nine-teenth hole that gated communities such as the one that I walked around today "will be the last outposts when everything goes to hell like in Rhodesia" (e.g., Informant 6, personal communication). The inability of some former citizens of Zimbabwe to refer to Zimbabwe as Zimbabwe is yet one more marker of the South African habitus. It indicates a denial of cultural and political change and instantly gives an individual the status of a "when we," i.e. "when we were in Rhodesia." It is perhaps the fear of waiting for what has occurred in Zimbabwe to happen in South Africa that informs the fortress mentality of some of the individuals that I am spending time with. As I am told about white farmers in their extended families "forcibly removed" from their land and the erosion of the free press in Zimbabwe, I am nudged and led to believe that this will possibly occur in South Africa as it is "only a matter of time." This predisposition is an indicator of another possible form of waiting and I speculate whether or not it is the dominant psychological condition that afflicts many of the gated community residents I speak with. It is a fear of waiting to be victims of what they deem oppression based on their race and the crimes committed by others in the past, or the impending and everyday fear of waiting to become victims of crime themselves. It could indicate a personality bound in conceptualizing one's self as a victim. Or, it could also indicate at times a convenient collective amnesia regarding the not so distant past that many white South Africans languish in to either appease guilt, or the loss of memory could provide the basis for a mental position from which to finally move on with what is perceived to be the business of the country. Regardless, it seems that waiting for crime to occur is the national pastime of South Africa.

The symbolic markers of crime prevention and the cultural markers of victim status abound throughout South Africa in the material form of razor wire and high walls surrounding residences. They are represented in the multiple security company placards that adorn closed gates andare emblazoned on patrol cars that outnumber local police. All of these symbols define a social space bound by a culture of fear while simultaneously demarcating an inaccessible place. Yet, there is a desire by residents to acknowledge these com- munities as something different than what they are, as the excerpts from one interview with a white female informant from the field site reveal:

Female Informant: This place is more like a suburb that just happens to have a boom gate at the one end. It's not like a special high-income group only.

Author: I remember you saying that the last time we chatted [...] that you thought of Springfield Hills more as just another suburb rather than a closed off gated community. But are there really different income groups here?

Female Informant: Yes and no, I mean [...] it has security. I mean instead of having the security around your house, you've got it around the whole estate. When we lived in another part of town I was unbelievably worried about crime and our house getting broken into. I was really paranoid and had terrible dreams and I actually hired a guard just to sit at the end of our driveway. It was a problem [...] it was a problem for my child you know. So, to move into Springfield Hills where I have the same thing but it is out of sight but just as effective [...] that's perfect for me. I don't feel trapped.

Author: So seeing the security all around has an effect on you [...]

Female Informant: It does [...] you feel trapped [...] all of the security reminds you of the crime all of the time, but it is not an idle fear - if that is the right term - it is very real. Jeepers [...] jaa [...] we bought a house in one of the best areas in Kloof and we chose that area because it was a good value and whatever but also because we thought it was a good area, there were no townships around and it was at the end of a dead end so no one would be walking through and there would be no through traffic and we had the most terrible experiences there and that is actually what made me so paranoid and fearful of crime and also 
having small kids of course.

You see, now there was a good area and it is not near the city centre [...] it's not really urban, it was quiet and lots of money obviously because there were wealthy houses there in the area and that is why I am sure that it was targeted [...] but I mean everywhere now there is a problem. The poorer areas are more of a problem because there are more poor people there and the wealthy areas are a problem because the poor people are trying to steal from the wealthy. Author: Were you upset when you had to leave that area or happy?

Female Informant: More angry than anything else [...] I mean I know this may sound rather harsh but I feel like I was forced to leave [...] I suppose that sounds terrible, that I was forced to live in a gated estate but that is the way I feel [...] but now I am happy to be here [...] look, my husband and I were on our way to Australia like so many others that you hear about but now I want to stay [...] I mean, I worry about whether or not my children have a future here but I still have hope in the new

country $[\ldots] 7$

7 E.g., Informant 7 (personal communication).

The conversation excerpt details three important research trajectories. First, that the primary reason for moving to a gated community rests on the psychological burden of perceiving one's self as a victim bound by a fear of crime. Consistently in interviews with parents, the protection of children and holding onto a cultural memory of a time when doors could be left unlocked and windows raised became the major reasons for living in communities like Springfield Hills. Second, some gated community residents feel as though they are victims of forced removal. The implications of making such a statement are uncomfortable and culturally loaded considering the socio-political history of South Africa. One must state immediately that it is problematic for a white woman possessing the resources to live in a gated community to claim this status because: (a) the move from one area to another is not state sanctioned and supported by a racist apartheid regime and (b) for a white South African to link herself to this segment of the country's history is questionable if not criminal. Yet, ethnographically, it is fascinating and provides a window into the mindset of many whites who feel that they are, or will be, victims of a new political system in which they are the new minorities and lack a voice or adequate representation. This was reflected in the recent national elections of 2004 as the New National Party and the Democratic Alliance, two primarily white parties, targeted the white demographic and used the fear of crime in their political promises addressing it as a primary issue in the elections. ${ }^{8}$

8 One only had to look at the racial dichotomy being portrayed on political placards and advertisements during the recent presidential election to see this.

The third research trajectory that emerges from this conversation, and repeated often during the course of fieldwork in this gated community, is the emigration tale. The emigration of white South Africans to countries such as the United States, New Zealand and Australia is a constant source of speculation as an indicator of the country's "brain drain" and shifting population dynamics. As I was told by one informant, one only has to look at the history of the political party currently known as the Democratic Alliance which was previously known as the Progressive Federal Party, or PFP at the time of the first democratic elections in 1994. PFP was also well regarded as an acronym for "Packed for Perth" as the majority of members of this political party were whites awaiting emigration clearance for Australia. Richard Ballard has even referred to the notion of "semigration" by white South Africans who move within the country to avoid what they consider newly inhospitable areas (Ballard, 2003). With this history in mind, what does it mean for a gated 
community resident in 2004 to express hope in the "New" South Africa, if possibly for themselves, but not necessarily their children? Could it be claimed that gated communities should be conceptualized as stopgap mechanisms for white emigration because they provide a safe place in contemporary South Africa? While I doubt that the construction of gated communities to prevent emigration will become the policy of the South African government, it is nonetheless an interesting speculation, if not a dream for developers.

\section{Conclusion}

This research has sought to provide some of the cultural context of gated community residents north of Durban in the KwaZulu-Natal province of South Africa. Introductory fieldwork in several communities, and concentrated participant observation in one particular estate, has led to a number of conclusions regarding the culture of gated community residents and institutional development issues. First, it needs to be recognized that gated communities are not homogenous white cultural bastions. While the majority of residents are white, it is simply too easy to reduce every other ethnic group within these environments by saying that gated community development is nothing but a reinscription of apartheid and the Group Areas Act. What this phenomenon does indicate is further contemplation over the concept of whiteness and its notion as a socially constructed concept that is bounded by class and culture in addition to actual skin tone. ${ }^{9}$

9 There is a large body of literature that discusses the alongside the exploration of racial dynamics in these communities.

It is also important to recognize that there are social tensions within gated communities, which also elides their perception as homogenous environments. Some of these tensions fall along ethnic and racial lines, while others are different in nature. While I have heard the classic fear from white residents that their " ethnic" neighbours might slaughter an animal in some religious ceremony, with the fear pronounced enough that there is a written prohibition on animal sacrifices in the published guideline for residents of the estate, many tensions are typical neighbourly complaints regarding noise, cars or simple annoyance. Essentially, it is too easy to reduce the construction of gated communities in South Africa to race and to state that the residents of these spaces are racially homogenous. Class on the other hand, does make a difference and further research hopes to complicate this notion alongside the exploration of racial dynamics in these communities.

While this research has focused on a segment of the white population in one gated community residence, there is an overwhelming need to talk about perspectives from other ethnic residents, domestic workers, security companies, developers and many others. ${ }^{10}$

10 I refer the reader to a forthcoming MA thesis by my student Nasseema Taleb at the University of KwaZulu-Natal focusing on Muslim identity in an adjoining gated community in the area.

In essence, all of these forces and social roles work in an interdependent fashion to form a network of power relations that situate the contemporary gated community development and resident (Foucault, 1993). By providing perspectives from white community members as well as others, many implications for identity in the "New" South Africa can be ascertained. This understanding of the everyday life of residents of gated com- munities leads one to understand how space actually becomes place and how attachment to place, whether home or refuge, develops over time, a notion of particular importance considering the history of South Africa. One can take an understanding of daily life within the gated 
communities of South Africa and use this to attempt to ascertain the context of people's lives outside of these spaces as they relate with other ethnic and racial groups in a variety of societal situations. The lives of everyone in South Africa are intimately connected to one another, not only evident in the utopic advertising that promotes the symbolic 10-year democracy marker and the security marketing of gated communities, but also through the intimate and forced attachment to whiteness that everyone that lived in South Africa had to adhere to under apartheid which guided the cultural patterns and lifestyles of individuals , the rules that people lived under, the language they were forced to learn, the friends they were allowed to have, and most importantly perhaps, the spaces were individuals were allowed or forced to live.

The unique social history of South Africa is entrenched in the negotiation and contestation of space, both in terms of its literal geographic and its abstract sense. Just as the cultural memory of suburban development incorporates inevitable connotations of whiteness bolstered by perceptions of crime, fear and flight; the cultural memory of apartheid coupled with the stereotypical unleashing of black crime and the perception that this legitimates security measures indicates a contemporary reality that must be negotiated in research. The gated community provides emblematic evidence of a problematic two nations dichotomy reinforced by housing in South Africa. As the shortage of housing for the black majority continues to plague the democratic government, the culture of fear among the white South African population supports rapid home development in gated community environments. As Landman has asked, the question remains whether the construction of gated communities creates bridges or barriers to social and political development in South Africa (Landman, 2002). The answer at this stage continues to support the notion that while gated community developments may appease the fear of a small number of South Africans they present more of a challenge as the new democratic government attempts to fill its mandate of creating a non-racial society and the elimination of poverty.

\section{Acknowledgments}

I would like to thank my informants and those who participated in this research. I would also like to thank Laura Bruni, Huffa Frobes-Cross, Nasseema Taleb, Mick Francis, Richard Ballard, Fran Rothstein and Setha Low for comments on previous drafts and continued support. I would also like to acknowledge support from a Mellon Postdoctoral Fellowship and the CCMS program at the University of KwaZulu-Natal during the research period.

\section{References}

Aliber, M., \& Mokoena, R. (2003). The land question in contemporary South Africa. In: J. Daniel, A. Habib, \& R. Southall (Eds.), State of the nation: South Africa 20032004 (pp. 330-346). Cape Town: Human Science Research Council.

Anderson, B. (1983). Imagined communities. New York: Verso.

Ballard, R. (2003). Emigration, semigration, assimilation and integration-Finding a comfort zone. Presented at performances of race in post-apartheid South African culture symposium, Cape Town.

Blakely, E. J., \& Snyder, M. G. (1997). Fortress America: Gated communities in the United States. Washington: The Brookings Institute.

Bourdieu, P. (1990). The logic of practice. Stanford: Stanford University Press (trans. by Richard Nice).

Brodkin, K. (1998). How Jews became White Folks and what that says about race in America. New Brunswick: Rutgers University Press. 
Caldeira, T. (1996). Fortified enclaves: The new urban segregation. Public Culture, 8(2), 303-328

Crapanzano, V. (1985). Waiting: The whites of South Africa. London: Granada.

Daniel, J., Habib, A., \& Southall, R. (Eds.) (2003). State of the nation: South Africa 2003-2004. Cape Town: Human Science Research Council.

Desai, A., (2000). We are the poors: Community struggles in post-apartheid South Africa. New York: Monthly Review Press.

Elder, G. (1997). The South African body politic: Exploring the spatial links between racism and compulsory heterosexuality. In: S. Pile, \& H. Nast (Eds.), Mapping bodies. New York: Routledge.

Fine, M. (Eds.) (1997). Off white: Readings on society, race and culture. New York: Routledge.

Foucault, M. (1979). Discipline and punish: The birth of the prison. New York: Vintage Books

Foucault, M. (1993). Space, power and knowledge. In: S.During (Eds.), The cultural studies reader (pp. 161- 169). New York: Routledge.

Frankenberg, R. (1993). The social construction of white- ness: White women, race matters. Minnesota: Univer- sity of Minnesota Press.

Freund, B., \& Pacayachee, V., (Eds.) (2002). (D)urban vortex: South African city in transition. Pietermaritz- burg: University of Natal Press.

Glassman, B. (1999). The culture of fear. New York: Basic Books.

Hindson, D., \& McCarthy, J. (1994). Here to stay: Informal settlements in KwaZulu-

Natal. Durban: Indicator Press.

Hook, D., \& Vrdoljak, M. (2001). Fear and loathing in Northern Johannesburg: The security park as heterotopia. Psychology in Society, 27, 61-83.

Landman, K. (2000a). Aspects of city life: The urban future; enclosed neighborhoods? Paper presented at urban futures conference, Johannesburg, South Africa.

Landman, K. (2000b). Gated communities and urban sustainability: Taking a closer look at the future. Presented at 2nd Southern African conference on sustainable development in the built environment strategies for a sustainable built environment, Pretoria South Africa.

Landman, K. (2002). Gated communities in South Africa: Building bridges or barriers? Paper presented at international conference on private urban governance, Mainz, Germany.

Low, S. (1997). Urban fear: Building fortress America. City and Society (pp. 52-72). Annual Review of the American Anthropological Association, Washington, DC.

Low, S. (2003a). Behind the gates: The new American dream. London: Routledge.

Low, S. (2003b). The edge and the center: Gated com- munities and the discourse of urban fear. In: S. Low, \& D. Lawrence-Zuniga (Eds.), The anthropology of space and place: Locating culture (pp. 387-407). Ox- ford: Blackwell Publishers.

Low, S., \& Zuniga, D.L. (Eds.) (2003). The anthropology of space and place: Locating culture. Oxford: Black- well Publishers.

Munn, N. (1996). Excluded spaces: The figure in the Australian aboriginal landscape. Critical Inquiry, 22, 446-465.

Nattrass, N. (2003). The state of the economy: A crisis of employment. In: J. Daniel, A. Habib, \& R. Southall (Eds.), State of the nation: South Africa 2003-2004 (pp. 141-147). Cape Town: Human Science Research Council.

Soja, E. (1989). Postmodern geographies: The reassertion of space in critical social theory. London: Verso. 